\title{
NOVEL SYNTHESIS OF SUBSTITUTED PYRROLE BOUND TO INDOLINONE VIA MOLECULAR IODINE-CATALYZED REACTION
}

\author{
Bimal K. Banik*, Isabella Garcia ${ }^{\mathrm{a}}$, Frances R. Morales', and Calista Aguilar ${ }^{\mathrm{a}}$ \\ Department of Chemistry, The University of Texas- Pan American, 1201 West University Drive, \\ Edinburg, Texas 78541, USA \\ "Undergraduate research participants \\ Phone: 956-618-7841; Fax: 956-384-5006, E-mail: banik@panam.edu
}

\begin{abstract}
An expeditious synthesis of indolinone bound to pyrrole starting from isatin and 4-hydroxyproline via a molecular iodine-catalyzed reaction is described. A mechanism is postulated that describes the formation of ylide and zwitterion intermediates. It is suggested that iodine can catalyze several spontaneous processes.
\end{abstract}

Keywords: Pyrrole, Indolinone, Molecular Iodine, Catalysis

\section{Introduction}

Substituted pyrroles and indoles are important classes of heterocyclic compounds having many medicinal activities. ${ }^{1}$ A number of methods for the synthesis of substituted pyrroles are described in the literature. ${ }^{2}$ In contrast, synthesis of pyrroles bound to indole systems has not been yet explored. Conjugate addition reactions have been demonstrated for the synthesis of polysubstituted pyrroles. ${ }^{3}$ These compounds have also been prepared from transition metal intermediates, ${ }^{4}$ by reductive couplings, ${ }^{5}$ aza-Wittig reactions, ${ }^{6}$ and other multistep operations. ${ }^{7}$ However, the PaalKnorr reaction ${ }^{8}$ remains one of the most attractive and simple methods for the synthesis of pyrroles. A clay-mediated ${ }^{9}$ reactions and microwave irradiation method ${ }^{10}$ have been used for the construction of pyrroles following Paal-Knorr conditions. In this paper, we describe the preparation of pyrroles bound to indolinone via molecular iodine-catalyzed reaction in excellent yield.

\section{Results}

We performed a structure-activity relationship study of various polyaromatic derivatives easily prepared from their corresponding amines in a projected route toward the development of novel anticancer agents. "It was demonstrated that modification of the heterocyclic ring is crucial in determining the biological activity of these derivatives (Scheme1). Based on the anticancer activities of these derivatives, we became interested in the synthesis of pyrroles bound to the polyaromatic amines of different structures. ${ }^{12}$ We envision that our work on iodine-catalyzed organic transformations can be used to achieve this goal (Scheme-2).

It has been demonstrated that primary amine 4 reacts with hexane-2,4-dione 5 in the presence of iodine or montmorriellonite KSF clay very efficiently to afford $N, 2,5$-trisubstituted pyrrole. ${ }^{12}$ In this reaction, iodine acts as an acidic catalyst. Realizing the importance of pyrrole-containing compounds, this method has been extended to other keto compounds (Scheme-3). 


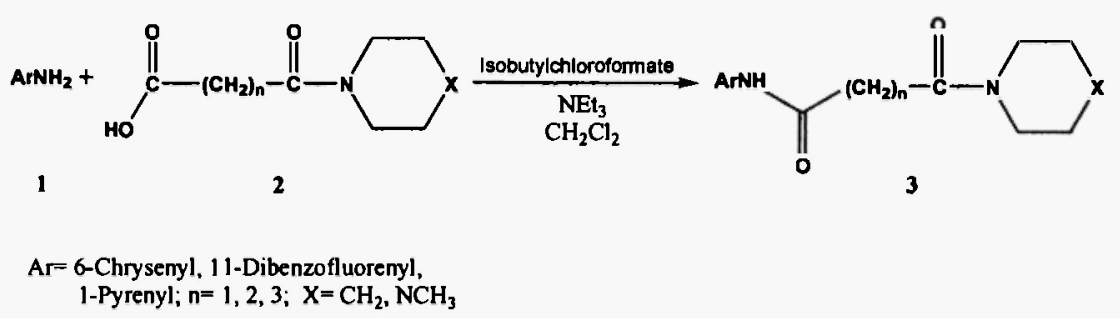

Scheme-1

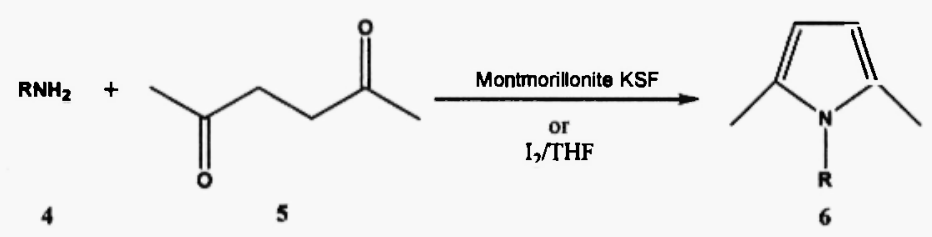

Scheme-2

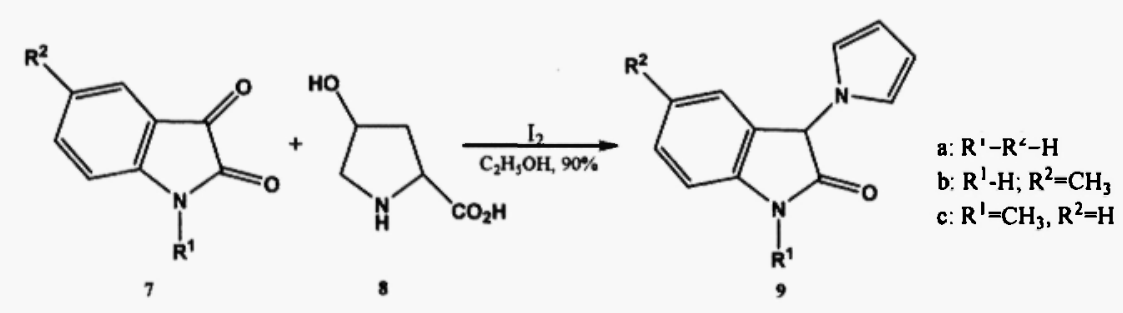

Scheme-3

\section{Discussion}

Isatin derivatives 7 are commercially available. The keto group of these compounds is very reactive. We found that 4-hydroxyproline 8 undergoes a reaction with isatin in the presence of catalytic amount of iodine in tetrahydrofuran or ethanol. The reaction proceeded better in ethanol. The structural analysis of the product indicated that a pyrrole ring is formed at the 3-position of the indole system 9. However, the reaction did not proceed without iodine. The structure of the product was confirmed by analysis of the ${ }^{1} \mathrm{H}$ NMR spectra. The singlet at $\delta 8.15$ indicated the presence of $\mathrm{NH}-$ group. This also confirmed that the $-\mathrm{NH}$ - group of the indole moiety remains unaltered during this reaction. The presence of 8-aromatic hydrogens was also established from the NMR spectra. The peaks at $\delta 6.9$ and 6.7 clearly indicated the presence of pyrrole moiety. The characteristic peak at $\delta 5.5$ confirmed the presence of a methine hydrogen in compound 9.

Clay-mediated synthesis of this type of compounds has been reported earlier. ${ }^{14}$ However, this type of method is not suitable for a relatively large scale of preparation. In this respects, iodine-catalyzed reaction for the synthesis of compounds 9 is significant since it can be performed on a multigram scale (2-10 g) with excellent yield. 


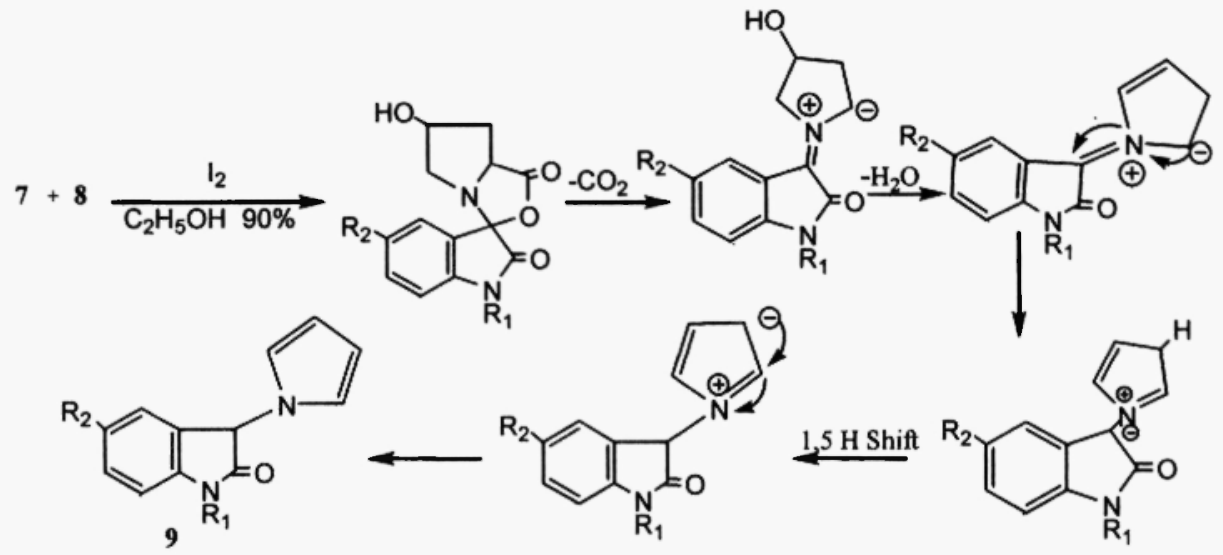

Scheme-4

A probable mechanism for this transformation is postulated in Scheme 4. It is based on our strategy on the protection of carbonyl derivatives with bifunctional compounds. ${ }^{13}$ The amino and the carboxy group are ideally located to undergo a condensation reaction to the highly reactive keto group of the indolinone moiety in the presence of iodine. On iodinecatalyzed condensation and under a high temperature, this intermediate can be transformed to an azomethine ylide via decarboxylation. Mild acid-induced dehydration at reflux temperature may yield a conjugated product spontaneously. 1,5-Proton shift may then occur to afford a zwitterionic intermediate that can easily isomerize to a stable aromatic product. ${ }^{14}$ This indicates the capability of the iodine as an activator in catalyzing several spontaneous processes as described in the present investigation.

\section{Conclusion}

We have demonstrated that two heterocycles, indole and pyrrole, can be fused in a one-step operation using a mild iodine-catalyzed reaction on a relatively large scale. Compounds described herein may demonstrate useful biological activities. We believe that our method can be applied to many other keto compounds.

\section{Experimental}

To isatin $(10 \mathrm{mmol})$, hydroxyproline $(10 \mathrm{mmol})$, and iodine $(200 \mathrm{mg})$ was added ethanol $(20 \mathrm{~mL})$ and the mixture was heated under reflux for $1 \mathrm{~h}$. Then the mixture was diluted with water $(6 \mathrm{~mL})$, extracted with dichloromethane $(2 \times 50$ $\mathrm{mL})$, and the extract was washed with sodium thiosulfate solution $(10 \%, 50 \mathrm{~mL})$, saturated sodium bicarbonate $(50 \mathrm{~mL})$, and dried $\left(\mathrm{Na}_{2} \mathrm{SO}_{4}\right)$. Pure product (approximately, $90 \%$ ) was isolated by silica gel column chromatography eluting with ethyl acetate/hexane (30/70).

All solvents and reagents were obtained from commercial sources and used without purification. Reactions were monitored by TLC using pre-coated silica gel aluminum plates containing a fluorescence indicator. 'H NMR spectra were recorded at $300 \mathrm{MHz}$ in $\mathrm{CDCl}_{3}$ using tetramethylsilane as an internal standard. IR spectra were expressed as wave numbers $\left(\mathrm{cm}^{-1}\right)$.

Compound 9a: mp: $140^{\circ} \mathrm{C}$, IR (KBr): 3295, 3190, $1711,1614,1482 \mathrm{~cm}^{-1} ;{ }^{1} \mathrm{H} \mathrm{NMR}{ }^{8} \mathrm{H}: 6.51$ (1H, s, CH), $6.25(2 \mathrm{H}$, br s, $\mathrm{CH}), 6.70(2 \mathrm{H}$, br s, $\mathrm{CH}), 6.85-7.34(4 \mathrm{H}, \mathrm{m}, \mathrm{ArH}), 8.87$ (1H, br s, NH).

Compound 9b: mp: $161^{\circ} \mathrm{C}$, IR (KBr): $3200,1708,1619,1487 \mathrm{~cm}^{-1} ;{ }^{1} \mathrm{H}$ NMR ${ }^{8} \mathrm{H}: 1.93\left(3 \mathrm{H}, \mathrm{s}, \mathrm{CH}_{3}\right), 5.58(1 \mathrm{H}, \mathrm{s}, \mathrm{CH})$, $6.25(2 \mathrm{H}, \mathrm{t}, \mathrm{J}=2.0 \mathrm{~Hz}, \mathrm{CH}), 6.71(2 \mathrm{H}, \mathrm{t}, \mathrm{J}=2.0 \mathrm{~Hz}, \mathrm{CH}), 6.79-7.31(4 \mathrm{H}, \mathrm{m}, \mathrm{ArH}), 9.09(1 \mathrm{H}, \mathrm{br} \mathrm{s}, \mathrm{NH})$. 
Compound 9c: mp: $135^{\circ} \mathrm{C}$, IR (KBr): 1712, 1606, $1486 \mathrm{~cm}^{-1}$; ${ }^{1} \mathrm{H}$ NMR ${ }^{8} \mathrm{H}: 3.23\left(3 \mathrm{H}, \mathrm{s}, \mathrm{CH}_{3}\right), 5.48(1 \mathrm{H}, \mathrm{s}, \mathrm{CH}), 6.22$ $(2 \mathrm{H}$, brs, $\mathrm{CH}), 6.68(2 \mathrm{H}$, brs, $\mathrm{CH}), 6.89-7.42(4 \mathrm{H}, \mathrm{m}, \mathrm{ArH})$; Anal. Calcd for $\mathrm{C}_{13} \mathrm{H}_{12} \mathrm{~N}_{2} \mathrm{O}: \mathrm{C}, 73.56 ; \mathrm{H}, 5.69 ; \mathrm{N}, 13.19$. Found: C, $73.40 ; \mathrm{H}, 5.51 ; \mathrm{N}, 13.00$.

\section{Acknowledgments}

We gratefully acknowledge the partial financial support for this research from the Robert A. Welch Fundation (BG0017) departmental grant, OBRR and Hispanic Health Research Center; supported by NIH NCMHD P20 MD00017004 located at Brownsville Regional Campus of the University Of Texas School of Public Health.

\section{REFERENCES}

1 C. Y. De Leon and B. Ganem, Tetrahedron 53, 7731 (1997); and references cited therein.

2 T. L. Gilchrist, J. Chem. Soc., Perkin Trans. 1615 (1998).

3 R. K. Dieter and H. Yu, Org. Lett. 2, 2283 (2000).

4 N. Iwasawa, K. Maeyama and M. Saitou, J. Am. Chem. Soc. 119, 1486 (1997).

5 A. Furstner, H. Weintritt and A. Hupperts, J. Org. Chem. 60, 6637 (1995).

6 A. Katritzky, J. Jiang and P. J. Steel, J. Org. Chem. 59, 4551 (1994).

7 M. Periasamy, G. Srinivas and P. Bharati, J. Org. Chem. 64, 4204 (1999).

8 J. V. Cooney and W. E. McEwen, J. Org. Chem. 46, 2570 (1981).

9 P. Ruault, J-F. Pilard, B. Touaux, F. T. Boullet and J. Hamelin, Synlett 935 (1994).

10 T. N. Danks, Tetrahedron Lett. 40, 3957 (1999).

11 I. Banik, F. F. Becker and B. K. Banik, J. Med. Chem. 46, 12 (2003); and references cited therein.

12 B. K. Banik, S. Samajdar and I. Banik, J Org. Chem. 69, 213 (2004).

13 (a) B. K. Banik, M. Fernandez and C. Alvarez, Tetrahedron Lett. 46, 2479 (2005); (b) B. K. Banik, M. Chapa, J. Marquez and M. Cardona, Tetrahedron Lett. 46, 2341 (2005); (c) S. Samajdar, M. K. Basu, F. F. Becker and B. K. Banik, Tetrahedron Lett. 42, 4425 (2001).

14 J. Azizian, A. R. Karimi, Z. Kazemizadeh, A. A. Mohammadi and M. R. Mohammadizadeh, J. Org. Chem. 70, 1471 (2005).

Received on March 17, 2007 